\title{
Long term clinical outcomes and associated predictors of progression free survival in anal canal cancer
}

\author{
Sara E. Beltrán Ponce ${ }^{1} \wedge$, Beth A. Erickson ${ }^{1}$, William A. Hall ${ }^{1}$, Meena Bedi ${ }^{1}$, Michael J. Martens ${ }^{2}$, \\ Malika Siker ${ }^{1}$, James Thomas $^{3}$, Ben George ${ }^{3}$, Kirk Ludwig ${ }^{4}$, Carrie Peterson ${ }^{4}$, Timothy Ridolf ${ }^{4}$, \\ John M. Longo ${ }^{1}$
}

${ }^{1}$ Department of Radiation Oncology, Medical College of Wisconsin, Milwaukee, WI, USA; ${ }^{2}$ Division of Biostatistics, Institute for Health \& Equity, Medical College of Wisconsin, Milwaukee, WI, USA; ${ }^{3}$ Division of Hematology and Oncology, Department of Medicine, Medical College of Wisconsin, Milwaukee, WI, USA; ${ }^{4}$ Division of Colorectal Surgery, Department of Surgery, Medical College of Wisconsin, Milwaukee, WI, USA

Contributions: (I) Conception and design: SE Beltrán Ponce, BA Erickson, M Siker, JM Longo; (II) Administrative support: None; (III) Provision of study materials or patients: SE Beltrán Ponce, BA Erickson, WA Hall, J Thomas, B George, K Ludwig, C Peterson, T Ridolfi, JM Longo; (IV) Collection and assembly of data: SE Beltrán Ponce, M Bedi, JM Longo; (V) Data analysis and interpretation: SE Beltrán Ponce, WA Hall, MB, MM, JM Longo; (VI) Manuscript writing: All authors; (VII) Final approval of manuscript: All authors.

Correspondence to: John M. Longo. Specialties Clinic Building-Radiation Oncology, 9200 West Wisconsin Avenue, Milwaukee, WI 53226, USA. Email: jlongo@mcw.edu.

Background: Reports of long term clinical outcomes for patients with squamous cell carcinoma (SCC) of the anal canal treated with chemotherapy and intensity modulated radiation therapy (IMRT) are limited. Pre-treatment hematologic variables associated with outcomes remain understudied. We sought to report the long-term clinical outcomes of a cohort of patients treated with definitive chemoradiation (CRT) utilizing helical tomotherapy (HT) IMRT at a single tertiary referral center. We further sought to examine for any correlations between pre-treatment hematologic parameters and progression free survival (PFS).

Methods: Data from patients with SCC of the anal canal treated with definitive CRT using HT IMRT from 2005 to 2017 were collected. Pre-treatment patient characteristics examined for correlations with PFS included: hemoglobin (Hgb) level, age, diabetes mellitus (DM) status, smoking status, neutropenia, thrombocytopenia, leukopenia, neutrophil/lymphocyte ratio, neutrophil/WBC ratio, lymphocyte/WBC ratio, sex, transplant status, HIV status, Karnofsky performance score, T-stage, and N-stage. Pre-treatment Hgb levels were recorded within two weeks prior to starting CRT. Clinical outcomes, including PFS, were described using the Kaplan-Meier estimator. A multivariable (MVA) Cox model of PFS evaluated the impact of pre-treatment $\mathrm{Hgb}$ and diabetes while adjusting for T-stage and age.

Results: The median patient age was 57 years old (range, 26-87) and there were 39 females (63.9\%) with the remaining patients identifying as males. Median patient follow up was 5.8 years. The PFS was $83 \%$ at 5 years. The median pre-treatment $\mathrm{Hgb}$ was $13 \mathrm{~g} / \mathrm{dL}$. On multivariable analysis (MVA), $\mathrm{Hgb} \leq 10 \mathrm{~g} / \mathrm{dL}$ (HR: 11.891, 95\% CI: 2.649-53.391, $\mathrm{P}=0.001$ ) and a diagnosis of diabetes mellitus (HR: 4.524, 95\% CI: 1.436-14.252, $\mathrm{P}=0.010$ ) were both significantly associated with a worse PFS. These factors were independent of T-stage and age.

Conclusions: Long-term clinical outcomes for patients with SCC of the anal canal treated with definitive CRT are presented. Pre-treatment hemoglobin of $\leq 10 \mathrm{~g} / \mathrm{dL}$ and diabetes were both independently associated with worse PFS on MVA. This retrospective data supports further prospective study of the impact of hematologic markers and medical co-morbidities such as DM and their management on clinical outcomes for patients with SCC of the anal canal treated with curative-intent CRT.

Keywords: Chemoradiation; anal canal carcinoma; HPV-mediated cancers

\footnotetext{
$\wedge$ ORCID: 0000-0002-1558-1130.
} 
Submitted Aug 12, 2021. Accepted for publication Dec 22, 2021.

doi: 10.21037/jgo-21-482

View this article at: https://dx.doi.org/10.21037/jgo-21-482

\section{Introduction}

Squamous cell carcinoma (SCC) of the anal canal is a relatively rare malignancy with an estimated annual incidence of 9,090 cases per year in the United States with a female predominance $(6,070$ cases per year) (1). The standard of care for curative management of non-metastatic SCC of the anal canal is chemoradiation (CRT) (2). Reports regarding long term progression free survival outcomes for patients with SCC of the anal canal treated utilizing intensity modulated radiation therapy (IMRT) and chemotherapy are limited.

Well known risk factors for anal SCC include immunosuppression, cigarette smoking, high risk sexual practices, and human papilloma virus (HPV) infection (3). Each of these risk factors, as well as hematologic markers, are well known to influence the response to definitive CRT in multiple other malignancies. For example, the relationship between anemia and poor outcomes in cervical cancer patients treated with CRT has been widely reported and well established. Pre-treatment anemia in cervical cancer patients treated with CRT is associated with increased locoregional recurrence and decreased progression free survival (PFS) and overall survival (OS) and is also associated with a nearly 2 -fold increase in mortality (4-8). Other hematologic toxicities including leukopenia have demonstrated a similar detrimental impact on cervical cancer survival $(9,10)$. A neutrophil to lymphocyte ratio of greater than 4 has also been associated with a poorer PFS and OS in many solid tumors (11-14).

The impact of hematologic variables on anal cancer outcomes is not well-characterized. A low pre-treatment hemoglobin was shown to be an independent risk factor for decreased PFS and OS in two single-institution studies with modest median follow-up of 52 and 27 months, respectively, and OS alone in a third study (15-17). Similarly, anemia that develops during treatment has been identified as an independent prognostic factor for SCC of the anal canal outcomes (18). Other series suggest that a higher neutrophil to lymphocyte ratio, leukocytosis, and neutrophilia are associated with poorer clinical outcomes (19-22). This retrospective study aims to present long-term clinical outcomes of patients treated with definitive CRT using helical tomotherapy (HT) intensity modulated radiation therapy (IMRT). Moreover, we sought to better characterize the influence of pre-treatment patient characteristics and hematologic parameters on PFS in patients with SCC of the anal canal. We present the following article in accordance with the STROBE reporting checklist (available at https:// jgo.amegroups.com/article/view/10.21037/jgo-21-482/rc).

\section{Methods}

From September 2005 to June 2017, data were collected from patients with SCC of the anal canal who received CRT with curative intent at a single tertiary referral center. Systemic therapy consisted of 1 or 2 cycles of mitomycin$\mathrm{C}$ (MMC) on days 1 and 29 of treatment and continuous infusion 5-fluorouracil (5-FU) on days $1-4$ and 29 in addition to radiation therapy. Radiation treatment planning was performed in parallel to the RTOG 0529 protocol utilizing HTIMRT (23). This radiation technique delivers dose in a helical or spiral formation to help deliver high doses to tumors while sparing normal tissues as much as possible. Pre-treatment hematologic metrics were recorded within two weeks of the initiation of CRT and were available for all patients. Treatment-related anemia was classified according to CTCAEv4.0 utilizing Hgb nadir during CRT treatment and within 3 months of the completion of therapy. A weekly complete blood count (CBC) was obtained for each patient per institutional protocol, and all values were reviewed to determine hematologic nadirs. Following completion of definitive CRT, patients were seen by medical oncology, radiation oncology, and surgical oncology with interval clinical exams, anoscopy, labs and imaging in accordance with NCCN surveillance guidelines (2). Recurrence was defined as evidence of biopsy proven SCC of the anal canal after previous complete response to therapy.

\section{Statistical analysis}

Patient and treatment related characteristics were summarized using descriptive statistics. PFS and OS postdiagnosis were evaluated using the Kaplan-Meier estimator, with patients who were event free being censored at the 
time of last follow-up. PFS was defined as freedom from death and progression of malignancy with both considered as events in this outcome. The prognostic value of clinical and hematologic variables on PFS and OS was assessed using univariable (UVA) Cox proportional hazards models.

Clinical variables collected and analyzed include pretreatment hemoglobin level, age, diabetes mellitus (DM) status, smoking status, on-treatment anemia, neutropenia, thrombocytopenia, leukopenia, neutrophil/lymphocyte ratio, neutrophil/WBC ratio, lymphocyte/WBC ratio, sex, transplant status, HIV status, Karnofsky Performance Score (KPS), disease stage, prior organ transplant, and lymph node involvement. In addition, the number of treatment breaks and total number of days on break were included. These variables were selected and analyzed due to their potential impact on the development of SCC of the anal canal, acute and late treatment-related toxicity, and survival outcomes. As DM has been shown to impact treatment response and outcomes in other gastrointestinal malignancies, the relationship between DM and SCC of the anal canal was of particular interest (24-26). Pre-treatment hemoglobin and age were treated as dichotomous in the Cox models based upon evaluations of the function forms of their effects using Schoenfeld residuals, which indicated nonlinear effects of these variables that are better described using dichotomization.

A multivariable (MVA) Cox model evaluated the effects of pre-treatment hemoglobin level and diabetes status on PFS while adjusting for the known prognostic factors of disease stage and age. Given the sample size, it was not possible to fit an MVA with number of treatment breaks as an additional variable. The proportional hazards assumption was evaluated for each covariate in the Cox models. No violations of proportionality were found. Interactions between predictors were also assessed in the multivariable Cox model, with no significant effects found. Three variables had missing observations, including Karnofsky score, HIV status, and cell population ratios. For the former two, missingness was treated as a separate category to allow all observations to be included in the Cox models. Cell population ratios were treated as continuous in the models and missing ratios $(\mathrm{N}=6)$ were treated as missing completely at random. Statistical analyses were performed using SAS version 9.4 and $R$ version 3.5.2.

\section{Ethical statement}

The study was conducted in accordance with the
Declaration of Helsinki (as revised in 2013). It was approved by the institutional ethics board of the Medical College of Wisconsin (PRO00022327) and a waiver of informed consent was granted based on minimal risk and the retrospective nature of the study.

\section{Results}

A total of 61 patients with SCC of the anal canal were available for analysis. The median follow up was 5.8 years (range 0.5 to 14.3 years). The median age at diagnosis was 57 years old with a range from 26 to 87 . Fourteen patients had diagnoses for which they were considered immunocompromised: 13 (21\%) were HIV-positive, $5(8 \%)$ were past transplant recipients, and $11(18 \%)$ were previously diagnosed with DM. One patient had inflammatory bowel disease. Within the HIV positive cohort $(\mathrm{N}=13)$, all patients were on anti-retroviral therapy with 12 (92\%) having documented medication compliance. Of note, 24 patients had unknown HIV status and therefore are not able to be included in these statistics. CD4 counts and viral loads before, during, and after treatment were not consistently obtained or available in the medical record.

Fifty-nine patients received MMC and 5-FU while the other two patients received alternative chemotherapies, one receiving 5-FU alone and one receiving capecitabine in addition to mitomycin-C. Twenty-five of the $59(42 \%)$ only received one dose of MMC. All patients received radiation therapy per institutional protocol. The median pre-treatment $\mathrm{Hgb}$ was $13 \mathrm{~g} / \mathrm{dL}$ and ranged from 8.5 to $16.2 \mathrm{~g} / \mathrm{dL}$. Eight patients had a pre-treatment Hgb of $\leq 10 \mathrm{~g} / \mathrm{dL}$ Additional patient characteristics are summarized in Table 1.

A total of 15 patients (25\%) had disease progression, with an average time to progression of 37.5 months from date of diagnosis, recorded as date of positive biopsy. The estimated PFS was $83 \%$ at 5 years and $64.4 \%$ at 10 years. A total of 11 patients $(18 \%)$ died with an average time to death of 46.6 months from date of diagnosis; all 11 deceased patients had disease progression prior to death. Estimated survival at 5 years was $87.3 \%$ and 10 years was $70.4 \%$.

With regard to hematologic toxicity, fifty four (89\%) patients experienced anemia, with 19 (31\%) having $\geq$ grade 3 treatment-related anemia. Complete review of hematologic toxicities are summarized in Table 2. The mean neutrophil/lymphocyte ratio was 2.8 prior to treatment and increased to 8.6 post-treatment. 
Table 1 Baseline characteristics

\begin{tabular}{|c|c|}
\hline Characteristics & Total (N=61), N (\%) \\
\hline \multicolumn{2}{|l|}{ Sex } \\
\hline Female & $39(63.9 \%)$ \\
\hline Male & $22(36.1 \%)$ \\
\hline \multicolumn{2}{|l|}{ Age at diagnosis (years) } \\
\hline Mean [standard deviation (SD)] & $57.8(12.8)$ \\
\hline Median (range) & $57.1(26.1,87.4)$ \\
\hline 56 years or less & $28(45.9 \%)$ \\
\hline Over 56 years & $33(54.1 \%)$ \\
\hline \multicolumn{2}{|l|}{ Karnofsky performance score } \\
\hline $90-100$ & $35(57.4 \%)$ \\
\hline Less Than 90 & $12(19.7 \%)$ \\
\hline Unknown & $14(23.0 \%)$ \\
\hline \multicolumn{2}{|l|}{ Tumor stage } \\
\hline $\mathrm{T} 1-2$ & $37(60.7 \%)$ \\
\hline T3-4 & $24(39.3 \%)$ \\
\hline \multicolumn{2}{|l|}{ Smoking history } \\
\hline Never smoked & $21(34.4 \%)$ \\
\hline Current or former smoker & $40(65.6 \%)$ \\
\hline \multicolumn{2}{|l|}{ Diabetes status } \\
\hline Not diabetic & $50(82.0 \%)$ \\
\hline Diabetic & $11(18.0 \%)$ \\
\hline \multicolumn{2}{|l|}{ Pre-treatment hemoglobin level } \\
\hline Hemoglobin $>10.0 \mathrm{~g} / \mathrm{dL}$ & $53(86.9 \%)$ \\
\hline Hemoglobin $\leq 10.0 \mathrm{~g} / \mathrm{dL}$ & $8(13.1 \%)$ \\
\hline \multicolumn{2}{|l|}{ HIV status } \\
\hline Negative or unknown & $48(78.7 \%)$ \\
\hline Positive & $13(21.3 \%)$ \\
\hline \multicolumn{2}{|c|}{ Lymphocyte/white blood cell (WBC) ratio } \\
\hline Mean (SD) & $27.4 \%(10.1 \%)$ \\
\hline Median (Range) & $26.0 \%(11.0 \%, 55.0 \%)$ \\
\hline \multicolumn{2}{|l|}{ Neutrophil/WBC ratio } \\
\hline Mean (SD) & $62.4 \%(11.5 \%)$ \\
\hline Median (range) & $64.0 \%(28.0 \%, 82.0 \%)$ \\
\hline \multicolumn{2}{|l|}{ Neutrophil/lymphocyte ratio } \\
\hline Mean (SD) & $279.5 \%(155.9 \%)$ \\
\hline Median (range) & $245.0 \%(50.9 \%, 696.8 \%)$ \\
\hline \multicolumn{2}{|l|}{ Number of treatment breaks } \\
\hline Mean (SD) & $1.4(1.6)$ \\
\hline Median (range) & $1.0(0.0,8.0)$ \\
\hline \multicolumn{2}{|c|}{ Total duration of treatment breaks (days) } \\
\hline Mean (SD) & $4.6(14.8)$ \\
\hline Median (range) & $1.0(0.0,113.0)$ \\
\hline
\end{tabular}

Pre-treatment $\mathrm{Hgb} \leq 10 \mathrm{~g} / \mathrm{dL}$ and $\geq$ grade 3 anemia were associated with inferior PFS on UVA [hazard ratio (HR): $6.925,95 \%$ CI: $2.27-21.125, \mathrm{P}<0.001$ and HR: 4.669, 95\% CI: $1.632-13.354, \mathrm{P}=0.004$, respectively]. These findings can be seen in Table 3 with estimated PFS curves for pre-treatment hemoglobin found in Figure 1. In addition, KPS less than 90 (HR: 4.590, 95\% CI: 1.39115.141, $\mathrm{P}=0.018$ ), diabetes status (HR: 3.669, 95\% CI: 1.288-10.448, $\mathrm{P}=0.015$ ), T3-4 tumor stage (HR: 3.488, 95\% CI: $1.212-10.040, \mathrm{P}=0.021)$, and number of treatment breaks (HR: 1.395, 95\% CI 1.047-1.857, $\mathrm{P}=0.023$ ) led to inferior PFS on UVA. Other hematologic markers such as thrombocytopenia, leukopenia, neutropenia, and neutrophil/lymphocyte ratio were not statistically associated with an impact on PFS in these patients. Similarly, current or past smoking history, age, gender, transplant status, HIV status, and total duration of treatment breaks did not impact PFS.

On MVA, pre-treatment anemia and DM status were associated with a significant detrimental impact on PFS (HR: 11.891, 95\% CI: 2.649-53.391, $\mathrm{P}=0.001$ and HR: 4.524, 95\% CI: $1.436-14.252, \mathrm{P}=0.010$, respectively) after adjustment for T-stage and age. The results of the MVA are summarized in Table 4.

Pre-treatment $\mathrm{Hgb} \leq 10 \mathrm{~g} / \mathrm{dL}$ and $\geq$ grade 3 anemia were also associated with inferior OS on UVA (HR 6.144, 95\% CI: $1.714-22.022, \mathrm{P}=0.005$ and HR 3.484, 95\% CI: 1.040-11.672, P=0.043, respectively). See Figure 2 for Kaplan Meier curves. In addition, KPS $<90$ was associated with worse OS on UVA (HR 19.844, 95\% CI: 3.185-123.61, $\mathrm{P}=0.004)$. See Table 5 for complete pre-treatment variable UVA.

\section{Discussion}

We have presented a cohort of patients with a median follow up of over 5 years, treated with modern CRT, in whom we detailed clinical variables and their associations with PFS. These data demonstrate that pre-treatment anemia and a diagnosis of DM were both associated with inferior PFS in SCC of anal canal. Long term PFS appears to be impacted substantially by these pre-treatment metrics. Interestingly, other common associations with clinical outcomes, such as T-stage, were not significantly associated with PFS on our MVA. Our series confirms the impact of anemia in patients with anal cancer that has been previously published and is the first to report the association of DM with inferior long term PFS $(18,19)$. 
Table 2 Summary of hematologic toxicities

\begin{tabular}{lcccc}
\hline Toxicity & $\begin{array}{c}\text { Number of patients } \\
\text { with any grade }\end{array}$ & $\begin{array}{c}\text { Percentage of patients } \\
\text { with any grade }\end{array}$ & $\begin{array}{c}\text { Number of patients with } \\
\geq \text { grade 3 }\end{array}$ & $\begin{array}{c}\text { Percentage of patients with } \\
\geq \text { grade 3 }\end{array}$ \\
\hline Treatment-related anemia & 54 & $88.5 \%$ & 19 & $31 \%$ \\
Febrile neutropenia & 14 & $23 \%$ & 14 & $23 \%$ \\
Leukopenia & 54 & $89 \%$ & 44 & $72 \%$ \\
Thrombocytopenia & 49 & $80 \%$ & 14 & $23 \%$ \\
Neutropenia & 52 & $85 \%$ & 41 & $67 \%$ \\
\hline
\end{tabular}

Table 3 Univariate Cox regression models of PFS

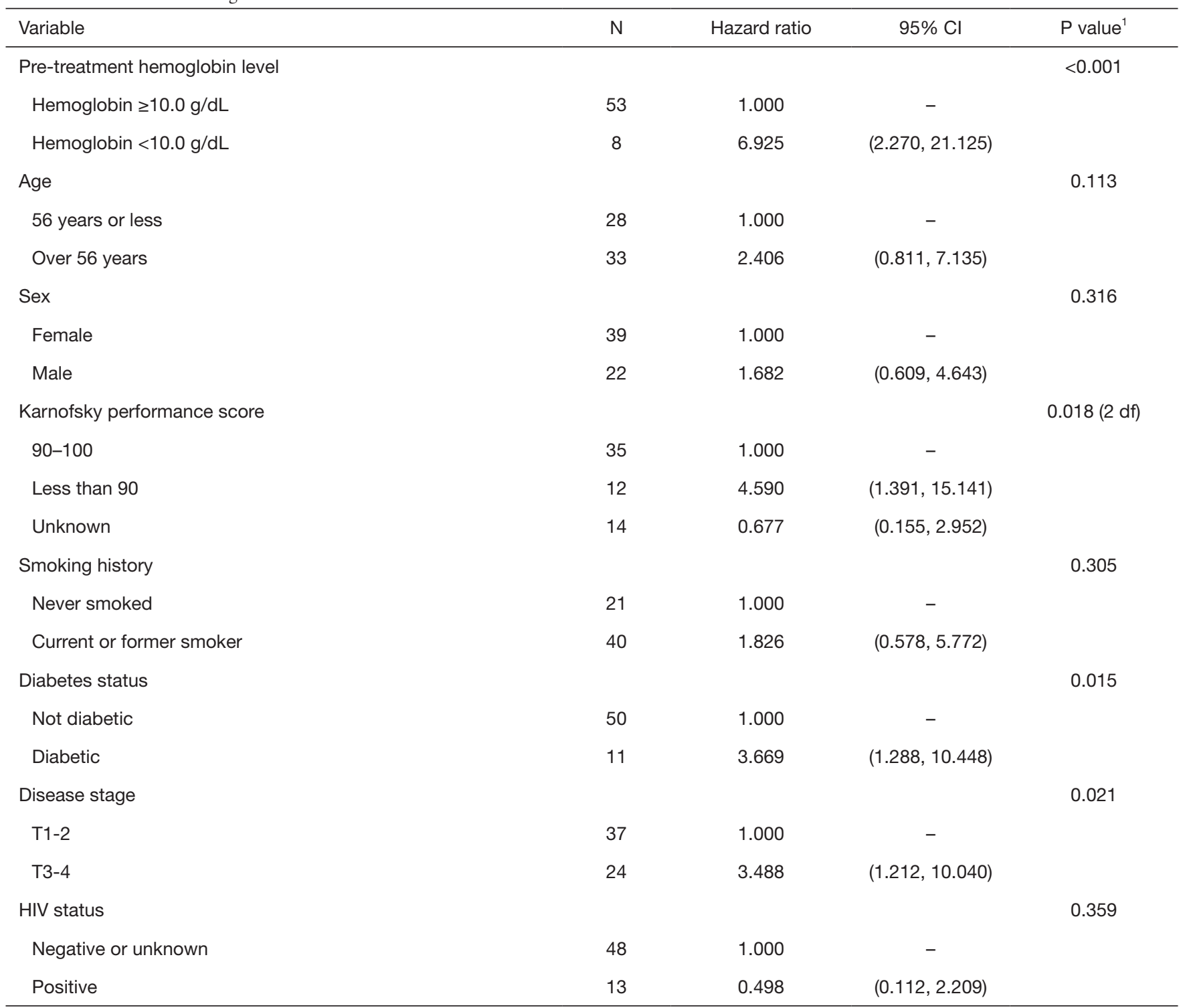

Table 3 (continued) 
Table 3 (continued)

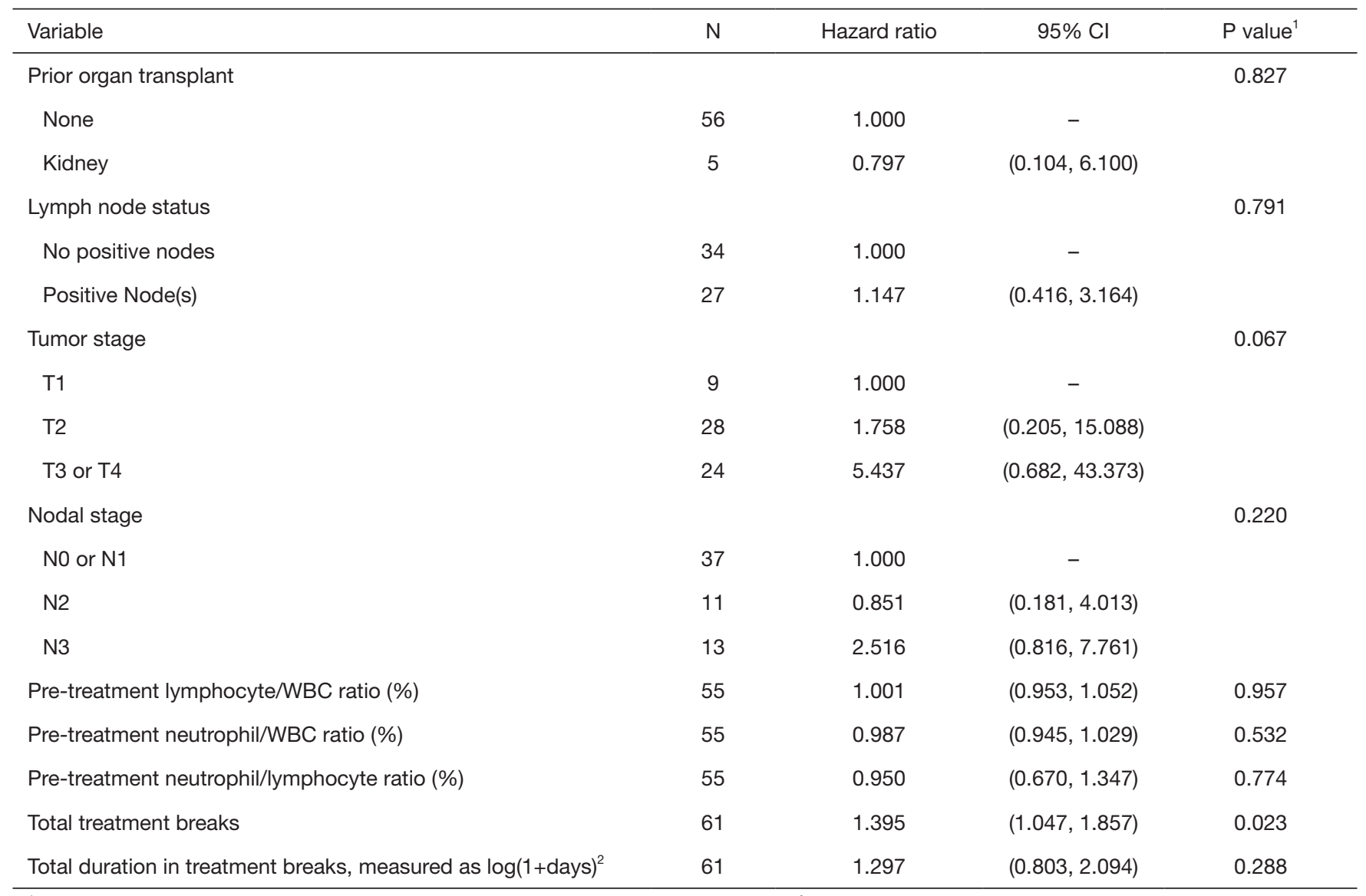

${ }^{1}, \mathrm{P}$ value obtained from Wald test of covariate effect estimate(s) in Cox model; ${ }^{2}, \log (1+\mathrm{x})$ transformation used to remove skewness and produce good model fit. PFS, progression-free survival.

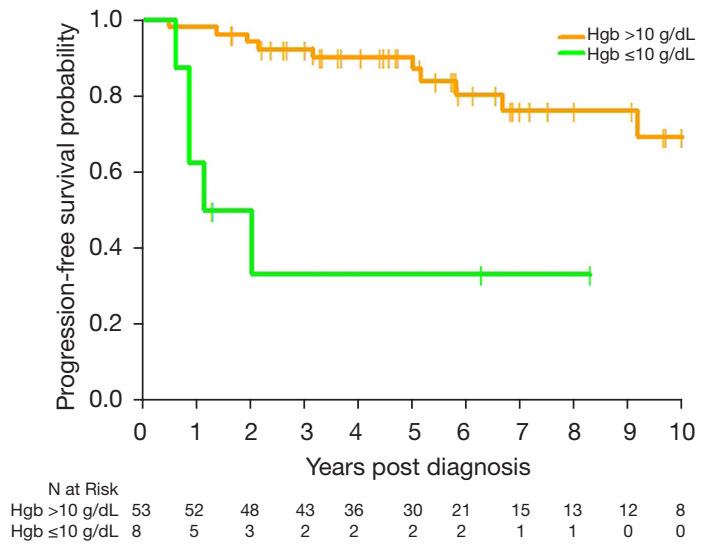

Figure 1 Estimated PFS curves by pre-treatment hemoglobin level stratified by less than or equal to (green) or greater than (orange) 10 for 10 years following completion of treatment. PFS, progression-free survival.
Given the poorer response to CRT and worse PFS and OS for patients caused by anemia in cervical cancer, hemoglobin is often corrected before beginning CRT in this setting $(4-8,27,28)$. Evidence supporting the benefit of anemia correction in cervical cancer is conflicting $(29,30)$. The impact of anemia on outcomes is postulated to be secondary to poor oxygenation and resultant tissue hypoxia, creating a tumor microenvironment that is less sensitive to radiation (31-33). When hypoxic tumor cells are treated with ionizing radiation, fewer free radicals are generated, causing less tumor cell DNA damage. Hypoxic cells are three times more resistant to radiation than non-hypoxic cells $(34,35)$. Therefore, anemia may dampen the effects of chemoradiation. The detrimental impacts of hypoxia on CRT efficacy have also been demonstrated in head and neck and bladder cancers $(36,37)$. The impact of tumor hypoxia 
Table 4 Multivariable Cox regression model of PFS

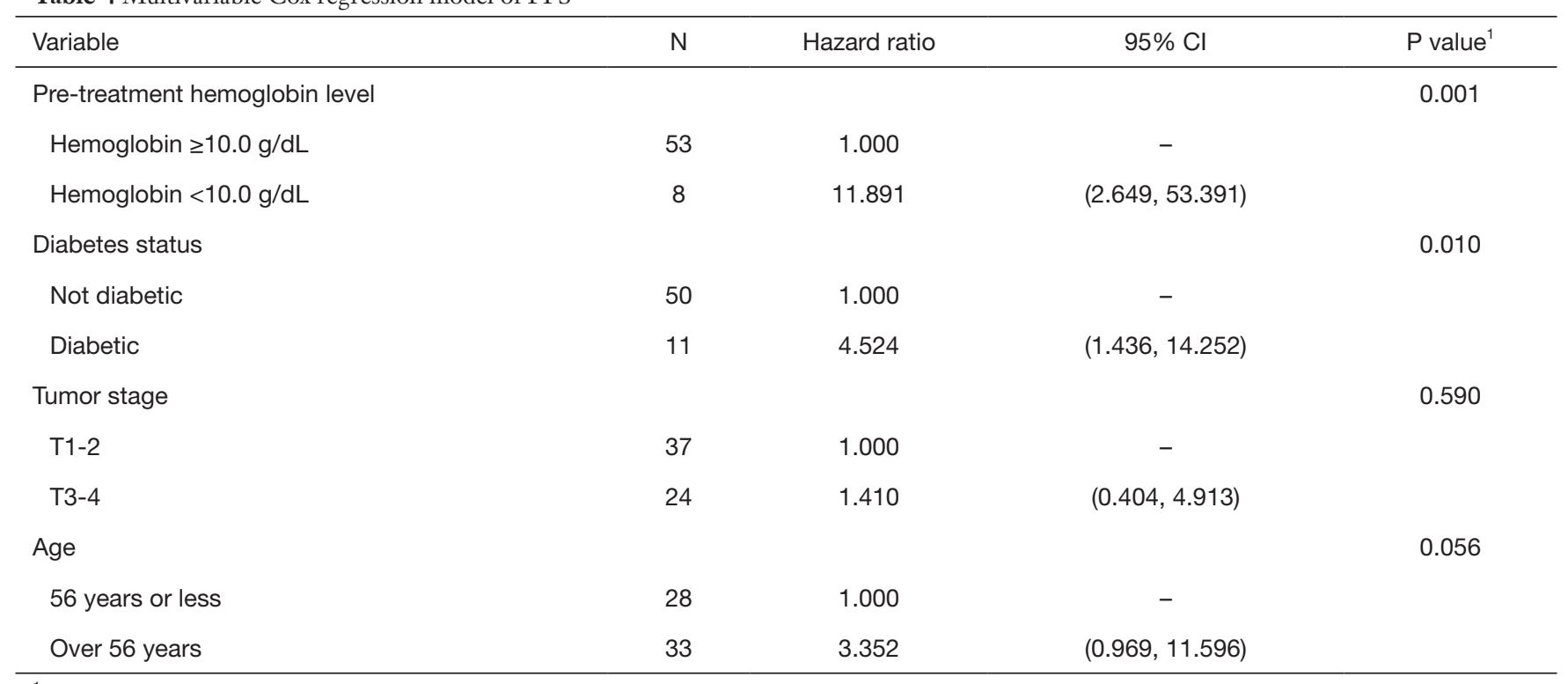

${ }^{1}$, P value obtained from Wald test of covariate effect estimate(s) in Cox model. PFS, progression-free survival.

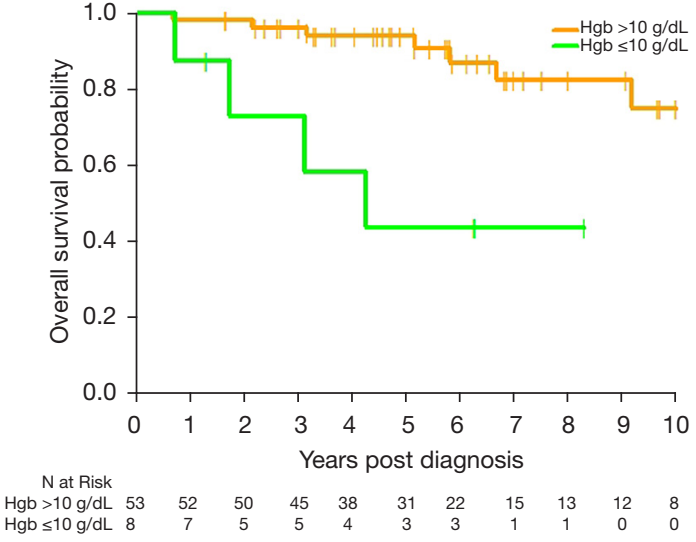

Figure 2 Estimated OS curves by pre-treatment hemoglobin level stratified by less than or equal to (green) or greater than (orange) 10 for 10 years following completion of treatment. OS, overall survival.

and SCC of the anal canal on treatment outcomes is not well-reported.

To our knowledge, the association between pre-treatment $\mathrm{DM}$ and PFS is novel. The presence of DM is well known to impact micro-vascular supply and consequently also influences tumor oxygenation in the microenvironment, aligning with similar etiologies as anemia. Interestingly, this association has also been in seen in patients with rectal adenocarcinoma, but the mechanism is not entirely clear $(24,25)$.
It is important to consider that anemia is a manifestation of chronic diseases and serves as a marker of overall worse performance status and increased mortality $(38,39)$. In our analysis, both diabetes and anemia were associated with inferior PFS, an effect that remained robustly significant on MVA.

Other hematologic disturbances were evaluated in our analysis, including the neutrophil/lymphocyte ratio, which was recorded before and after treatment. When the body experiences physiologic stress, such as cancer or cancer-related treatment, the neutrophil/lymphocyte ratio may increase. This can serve as a marker for increased physiological stress and potentially corresponds to inferior cancer outcomes (40). Clinical data regarding neutrophil/ lymphocyte ratio and outcomes has been variable especially when considering cancer type and age $(11,40)$. Our results did not find a correlation between the neutrophil/ lymphocyte ratio and cancer-related outcomes, which has not been previously reported for anal cancer.

This study has several limitations that are important to consider. First, this is a retrospective study that presents data from a single institution, and the sample size is small. With this sample size, there a limitation to the statistical power within certain tumor-stage related groups including $\mathrm{T}$ and $\mathrm{N}$ stage. This study design has inherent limitations such as selection bias and ascertainment bias and only includes patients who were candidates for and received CRT. In light of the limited sample size, it is difficult to characterize with 
Table 5 Univariate Cox regression models of OS by baseline variables

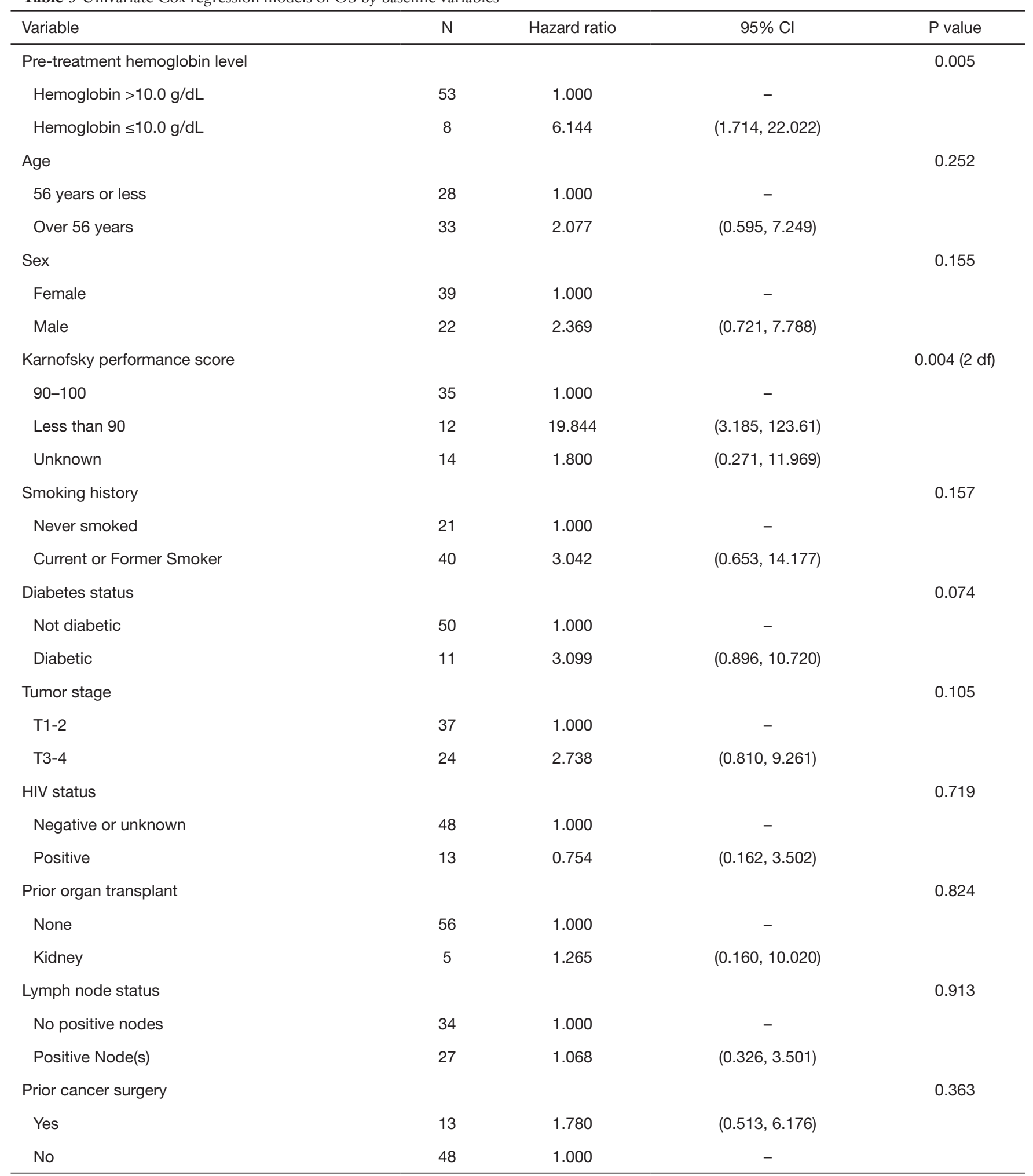

Table 5 (continued) 
Table 5 (continued)

\begin{tabular}{lccc}
\hline Variable & $\mathrm{N}$ & Hazard ratio & $95 \% \mathrm{Cl}$ \\
\hline T stage & & & - \\
T1 & 9 & 1.000 & $(0.155,12.510)$ \\
T2 & 28 & 1.392 & $(0.419,29.753)$ \\
T3 or T4 & 24 & 3.531 & 0.264 (ue \\
N stage & & & - \\
N0 or N1 & 37 & 1.000 & $(0.069,4.794)$ \\
N2 & 11 & 0.577 & $(0.736,9.441)$ \\
N3 & 13 & 2.637 & $(0.955,1.070)$ \\
Lymphocyte/WBC ratio (\%) & 55 & 1.011 & $(0.933,1.031)$ \\
Neutrophil/WBC ratio (\%) & 55 & 0.981 & $(0.606,1.424)$ \\
Neutrophil/lymphocyte ratio (\%) & 55 & 0.929 & 0.710 \\
\hline
\end{tabular}

${ }^{1}$, P value obtained from Wald test of covariate effect estimate(s) in Cox model. OS, overall survival.

certainty the relationship between cancer diagnosis, anemia, co-morbidities, and outcomes. This sample size also limited the ability to add additional variables to the MVA model, impacting the analysis of number of treatment breaks in this cohort. These findings should therefore be considered as hypothesis generating.

There are several strengths of this study that warrant careful consideration. First, is the median follow-up of 70 months. In reviewing the literature for institutional experiences treating anal cancer with CRT using IMRT, median follow-up is generally significantly more limited. With an estimated PFS of $83 \%$ at 5 years, this study provides long-term data on the risk of progression with the current standard of care treatment techniques. A recently published single institution series reported a limited median follow up of 7.5 months with $75 \%$ remaining disease free at that time (41). A similar study was published with a median follow-up of 26 months and a disease free survival of $86 \%$ (42). The longest located study had a median followup of 70 months with a DFS of $68 \%$ (43). Our study adds to the limited body of literature in this respect with long-term PFS outcomes in anal canal patients treated with IMRT. A second strength that should be carefully considered in this study is the quality of the clinical characteristics, specifically the hematologic characteristics. These types of metrics are somewhat rare in large prospective trials and have been underexplored with regard to their impact on oncologic specific endpoints, such as PFS. There is also novel literature exploring the biomolecular targets to further improve PFS and OS in SCC of the anal canal patients (44).

This study explored a variety of clinical features and found that anemia and DM led to decreased PFS in anal canal patients. Future studies should evaluate the impact of anemia and DM on outcomes in larger cohorts, seek to better understand the impact of DM on the tumor microenvironment, and investigate more aggressive anemia management in the setting of SCC of the anal canal.

\section{Acknowledgments}

Funding: None.

\section{Footnote}

Reporting Checklist: The authors have completed the STROBE reporting checklist. Available at https://jgo. amegroups.com/article/view/10.21037/jgo-21-482/rc

Data Sharing Statement: Available at https://jgo.amegroups. com/article/view/10.21037/jgo-21-482/dss

Conflicts of Interest: All authors have completed the ICMJE uniform disclosure form (available at https://jgo. amegroups.com/article/view/10.21037/jgo-21-482/coif). WAH has grant funding from the We Care Fund for Medical Innovation and Research, Elekta Instruments $\mathrm{AB}$, 
Advancing Healthier Wisconsin Research and Education Program and is a Co-I on R01CA247960 and R01CA24988 funded grants. All funding is paid to the institution. The other authors have no conflicts of interest to declare.

Etbical Statement: The authors are accountable for all aspects of the work in ensuring that questions related to the accuracy or integrity of any part of the work are appropriately investigated and resolved. This study was conducted in accordance with the Declaration of Helsinki (as revised in 2013). This study was approved by the institutional ethics board of the Medical College of Wisconsin (PRO00022327) and a waiver of informed consent was granted based on minimal risk and the retrospective nature of the study.

Open Access Statement: This is an Open Access article distributed in accordance with the Creative Commons Attribution-NonCommercial-NoDerivs 4.0 International License (CC BY-NC-ND 4.0), which permits the noncommercial replication and distribution of the article with the strict proviso that no changes or edits are made and the original work is properly cited (including links to both the formal publication through the relevant DOI and the license). See: https://creativecommons.org/licenses/by-nc-nd/4.0/.

\section{References}

1. Siegel RL, Miller KD, Fuchs HE, et al. Cancer Statistics, 2021. CA Cancer J Clin 2021;71:7-33.

2. Network NCC. Anal Carcinoma (Version 1.2021). 2021. Available online: https://www.nccn.org/professionals/ physician_gls/pdf/anal.pdf. Accessed June 28, 2021.

3. Tseng HF, Morgenstern H, Mack TM, et al. Risk factors for anal cancer: results of a population-based case-control study. Cancer Causes Control 2003;14:837-46.

4. Chen CC, Wang L, Lin JC, et al. The prognostic factors for locally advanced cervical cancer patients treated by intensity-modulated radiation therapy with concurrent chemotherapy. J Formos Med Assoc 2015;114:231-7.

5. Elmajjaoui S, Ismaili N, El Kacemi H, et al. Epidemiology and outcome of cervical cancer in national institute of Morocco. BMC Womens Health 2016;16:62.

6. Grigiene R, Valuckas KP, Aleknavicius E, et al. The value of prognostic factors for uterine cervical cancer patients treated with irradiation alone. BMC Cancer 2007;7:234.

7. Pomros P, Sriamporn S, Tangvoraphonkchai V, et al.
Factors affecting survival of cervical cancer patients treated at the radiation unit of Srinagarind Hospital, Khon Kaen University, Thailand. Asian Pac J Cancer Prev 2007;8:297-300.

8. Barkati M, Fortin I, Mileshkin L, et al. Hemoglobin level in cervical cancer: a surrogate for an infiltrative phenotype. Int J Gynecol Cancer 2013;23:724-9.

9. Krusun S, Pesee M, Supakalin N, et al. Treatment interruption during concurrent chemoradiotherapy of uterine cervical cancer; analysis of factors and outcomes. Asian Pac J Cancer Prev 2014;15:5653-7.

10. Hoskin PJ, Rojas AM, Peiris SN, et al. Pre-treatment haemoglobin and peripheral blood lymphocyte count as independent predictors of outcome in carcinoma of cervix. Clin Oncol (R Coll Radiol) 2014;26:179-84.

11. Templeton AJ, McNamara MG, Šeruga B, et al. Prognostic role of neutrophil-to-lymphocyte ratio in solid tumors: a systematic review and meta-analysis. J Natl Cancer Inst 2014;106:dju124.

12. Wu J, Chen M, Liang C, et al. Prognostic value of the pretreatment neutrophil-to-lymphocyte ratio in cervical cancer: a meta-analysis and systematic review. Oncotarget 2017;8:13400-12.

13. Huang QT, Man QQ, Hu J, et al. Prognostic significance of neutrophil-to-lymphocyte ratio in cervical cancer: A systematic review and meta-analysis of observational studies. Oncotarget 2017;8:16755-64.

14. Ittiamornlert $P$, Ruengkhachorn I. Neutrophil-lymphocyte ratio as a predictor of oncologic outcomes in stage IVB, persistent, or recurrent cervical cancer patients treated by chemotherapy. BMC Cancer 2019;19:51.

15. Oblak I, Cesnjevar M, Anzic M, et al. The impact of anaemia on treatment outcome in patients with squamous cell carcinoma of anal canal and anal margin. Radiol Oncol 2016;50:113-20.

16. Roldán GB, Chan AK, Buckner M, et al. The prognostic value of hemoglobin in patients with anal cancer treated with chemoradiotherapy. Dis Colon Rectum 2010;53:1127-34.

17. Franco P, Montagnani F, Arcadipane F, et al. The prognostic role of hemoglobin levels in patients undergoing concurrent chemo-radiation for anal cancer. Radiat Oncol 2018;13:83.

18. Glynne-Jones R, Sebag-Montefiore D, Adams R, et al. Prognostic factors for recurrence and survival in anal cancer: generating hypotheses from the mature outcomes of the first United Kingdom Coordinating Committee 
on Cancer Research Anal Cancer Trial (ACT I). Cancer 2013;119:748-55.

19. De Felice F, Rubini FL, Romano L, et al. Prognostic significance of inflammatory-related parameters in patients with anal canal cancer. Int J Colorectal Dis 2019;34:519-25.

20. Casadei-Gardini A, Montagnani F, Casadei C, et al. Immune inflammation indicators in anal cancer patients treated with concurrent chemoradiation: training and validation cohort with online calculator (ARC: Anal Cancer Response Classifier). Cancer Manag Res 2019;11:3631-42. Erratum in: Cancer Manag Res 2019;11:5123.

21. Schernberg A, Huguet F, Moureau-Zabotto L, et al. External validation of leukocytosis and neutrophilia as a prognostic marker in anal carcinoma treated with definitive chemoradiation. Radiother Oncol 2017;124:110-7.

22. Schernberg A, Escande A, Rivin Del Campo E, et al. Leukocytosis and neutrophilia predicts outcome in anal cancer. Radiother Oncol 2017;122:137-45.

23. Foundation R. A Phase II Evaluation of Dose-Painted IMRT in Combination with 5-Fluorouracil and Mitomycin-C for Reduction of Acute Morbidity in Carcinoma of the Anal Canal. 2011. Available online: https://www.rtog.org/ClinicalTrials/ProtocolTable/ StudyDetails.aspx? study=0529. Accessed June 28, 2021.

24. Caudle AS, Kim HJ, Tepper JE, et al. Diabetes mellitus affects response to neoadjuvant chemoradiotherapy in the management of rectal cancer. Ann Surg Oncol 2008;15:1931-6.

25. Skinner HD, Crane CH, Garrett CR, et al. Metformin use and improved response to therapy in rectal cancer. Cancer Med 2013;2:99-107.

26. Meyerhardt JA, Catalano PJ, Haller DG, et al. Impact of diabetes mellitus on outcomes in patients with colon cancer. J Clin Oncol 2003;21:433-40.

27. Grogan M, Thomas GM, Melamed I, et al. The importance of hemoglobin levels during radiotherapy for carcinoma of the cervix. Cancer 1999;86:1528-36.

28. Kapp KS, Poschauko J, Geyer E, et al. Evaluation of the effect of routine packed red blood cell transfusion in anemic cervix cancer patients treated with radical radiotherapy. Int J Radiat Oncol Biol Phys 2002;54:58-66.

29. Santin AD, Bellone S, Parrish RS, et al. Influence of allogeneic blood transfusion on clinical outcome during radiotherapy for cancer of the uterine cervix. Gynecol Obstet Invest 2003;56:28-34.
30. Lim MC, Kim JY, Kim TH, et al. Allogeneic blood transfusion given before radiotherapy is associated with the poor clinical outcome in patients with cervical cancer. Yonsei Med J 2008;49:993-1003.

31. Serkies K, Badzio A, Jassem J. Clinical relevance of hemoglobin level in cervical cancer patients administered definitive radiotherapy. Acta Oncol 2006;45:695-701.

32. Harrison LB, Chadha M, Hill RJ, et al. Impact of tumor hypoxia and anemia on radiation therapy outcomes. Oncologist 2002;7:492-508.

33. Vaupel P, Mayer A. Hypoxia in cancer: significance and impact on clinical outcome. Cancer Metastasis Rev 2007;26:225-39.

34. Dewhirst MW, Cao Y, Moeller B. Cycling hypoxia and free radicals regulate angiogenesis and radiotherapy response. Nat Rev Cancer 2008;8:425-37.

35. Rockwell S, Dobrucki IT, Kim EY, et al. Hypoxia and radiation therapy: past history, ongoing research, and future promise. Curr Mol Med 2009;9:442-58.

36. Lee WR, Berkey B, Marcial V, et al. Anemia is associated with decreased survival and increased locoregional failure in patients with locally advanced head and neck carcinoma: a secondary analysis of RTOG 85-27. Int J Radiat Oncol Biol Phys 1998;42:1069-75.

37. Pollack A, Zagars GK, Dinney CP, et al. Preoperative radiotherapy for muscle-invasive bladder carcinoma. Long term follow-up and prognostic factors for 338 patients. Cancer 1994;74:2819-27.

38. Penninx BW, Pahor M, Cesari M, et al. Anemia is associated with disability and decreased physical performance and muscle strength in the elderly. J Am Geriatr Soc 2004;52:719-24.

39. Westerlind B, Östgren CJ, Mölstad S, et al. Prevalence and predictive importance of anemia in Swedish nursing home residents - a longitudinal study. BMC Geriatr 2016;16:206.

40. Howard R, Kanetsky PA, Egan KM. Exploring the prognostic value of the neutrophil-to-lymphocyte ratio in cancer. Sci Rep 2019;9:19673.

41. Singh K, Sathyamurthy A, Ramireddy JK, et al. Outcomes of Squamous Cell Carcinoma Anal Canal treated with IMRT-VMAT-based Concurrent Chemoradiation: a Single Institutional Experience. J Gastrointest Cancer 2021. [Epub ahead of print].

42. Yucel S, Kadioglu H, Gural Z, et al. Outcomes of patients with anal cancer treated with volumetricmodulated arc therapy or intensity-modulated 
radiotherapy and concurrent chemotherapy. J Cancer Res Ther 2021;17:51-5.

43. de Meric de Bellefon M, Lemanski C, Castan F, et al. Long-term follow-up experience in anal canal cancer treated with Intensity-Modulated Radiation Therapy:

Cite this article as: Beltrán Ponce SE, Erickson BA, Hall WA, Bedi M, Martens MJ, Siker M, Thomas J, George B, Ludwig K, Peterson C, Ridolfi T, Longo JM. Long term clinical outcomes and associated predictors of progression free survival in anal canal cancer. J Gastrointest Oncol 2022;13(1):185-196. doi: 10.21037/ jgo-21-482
Clinical outcomes, patterns of relapse and predictors of failure. Radiother Oncol 2020;144:141-7.

44. Jones CM, Goh V, Sebag-Montefiore D, et al. Biomarkers in anal cancer: from biological understanding to stratified treatment. Br J Cancer 2017;116:156-62. 